\title{
Imaging Characteristics of Olfactory Neuroblastoma (Esthesioneuroblastoma)
}

\author{
Arthur B. Dublin ${ }^{1}$ Matthew Bobinski ${ }^{1}$
}

Address for correspondence Arthur B. Dublin, MD, MBA, FACR, Department of Radiology, Section of Neuroradiology, University of California-Davis Medical Center, Sacramento, CA, United States (e-mail: arthur.dublin@ucdmc.ucdavis.edu).

J Neurol Surg B 2016;77:1-5.
Abstract
Keywords
- olfactory
neuroblastoma
- esthesio-
neuroblastoma
- skull base
- imaging

This presentation outlines the clinical and imaging characteristics of esthesioneuroblastoma.

\section{Introduction}

Olfactory neuroblastoma, or esthesioneuroblastoma (ENB), is an uncommon malignant tumor of neural crest origin, arising from the olfactory epithelium of the superior nasal cavity. It accounts for $\sim 2$ to $6 \%$ of the intranasal tumors, with an incidence of $\sim 0.4$ per million. ${ }^{1-3}$ The age at presentation is bimodal in distribution in the second and sixth decades of life and without a gender predilection. ${ }^{4,5}$

\section{Staging}

The stage of the disease at the initial presentation is highly predictive of survival, and accurate staging is essential. The Kadish system is the most commonly used approach to classify the anatomical extent of ENB, although other classifications have been proposed. ${ }^{6-9}$ The Kadish staging uses three categories, group $\mathrm{A}, \mathrm{B}$, and $\mathrm{C}$, as follows: A, tumor confined to the nasal cavity; $B$, tumor extends into the paranasal sinuses; and $C$, tumor extends beyond the nasal cavity and paranasal sinuses including involvement of the cribriform plate, skull base, orbit, or intracranial cavity. The modified Kadish staging system includes a fourth stage for patients with nodal or distant metastases..$^{10}$ This system has been criticized because it requires surgical staging, does not routinely consider metastatic spread, and lacks prognostic value. Additionally, few patients at initial clinical discovery have group A disease if the staging is strictly applied because of a high incidence of ethmoid sinus involvement. Simon et al did not find a single patient in their 20-year experience that presented with stage A disease. ${ }^{5}$ Similar observations have been reported in other series, and the overall incidence of Kadish A disease is estimated at $5 \% .{ }^{11-14}$ Modern imaging makes a diagnosis of Kadish A disease less likely.

Despite the inadequacies and attempts to use a TNM classification, the Kadish staging is the most commonly used. $^{8}$ The Dulguerov staging system uses the TNM classification and includes the imaging data ( - Table 1$).{ }^{8}$ Some authors prefer the Dulguerov system because early involvement of the cribriform plate is recognized in the T2 stage, and intracranial but extradural tumors are separated from those with true brain involvement. ${ }^{15}$

\section{Clinical Presentation}

ENB presents with epistaxis, nasal obstruction, decreased olfactory function, diplopia, proptosis, or a combination of these symptoms. ${ }^{6,7,9,16}$ Local invasion occurs most frequently into the paranasal sinuses, orbits, and anterior cranial fossa. Metastatic disease most frequently involves local lymph nodes, with distant metastasis to the lungs, liver, and bone. ${ }^{1,6,8}$ The incidence of cervical lymph node metastasis ranges from 20 to $30 \%$ and reaches $44 \%$ in stage C. $2,6,8,17-19$ Howell et al described a predictable pattern of metastases to the cervical lymph nodes, typically involving level II nodes published online

September 14, 2015 (c) 2016 Georg Thieme Verlag KG Stuttgart · New York 
Table 1 Esthesioneuroblastoma staging system as proposed by Dulguerov ${ }^{8}$

\begin{tabular}{|l|l|}
\hline Staging & Description \\
\hline Primary tumor & $\begin{array}{l}\text { Tumor involving the nasal cavity and/or paranasal sinuses (excluding sphenoid), sparing the } \\
\text { most superior ethmoid }\end{array}$ \\
\hline T1 & $\begin{array}{l}\text { Tumor involving the nasal cavity and/or paranasal sinuses (including the sphenoid) with } \\
\text { extension to or erosion of the cribriform plate }\end{array}$ \\
\hline T2 & $\begin{array}{l}\text { Tumor extending into the orbit or protruding into the anterior cranial fossa, without dural } \\
\text { involvement }\end{array}$ \\
\hline T3 & Tumor involving the brain \\
\hline T4 & No cervical lymph node metastasis \\
\hline Lymph nodes & Any form of cervical lymph node metastasis \\
\hline N0 & \multicolumn{2}{|l}{} \\
\hline N1 & No metastases \\
\hline Distant metastasis & Distant metastases \\
\hline M0 &
\end{tabular}

(93\%), with frequent involvement of level I (57\%), level III (50\%), and retropharyngeal nodes $(43 \%){ }^{20}$

\section{Imaging}

Imaging plays a key role in the accurate staging of ENB including both computed tomography (CT) and magnetic resonance imaging (MRI). These imaging modalities should always be included to correctly assess the extent of the disease.
CT should be performed with thin slices ( $1 \mathrm{~mm}$ thick) and reformatted in both coronal and sagittal planes. ENB does not have specific CT characteristics, presenting initially as a homogeneous soft tissue mass in the nasal vault. However, CT is essential for evaluation of the osseous involvement of the cribriform plate, fovea ethmoidalis, and lamina papyracea (-Fig. 1). Bone remodeling without destruction is not uncommon, due to the indolent growth pattern in some cases. The mass shows moderate and uniform enhancement. Scattered
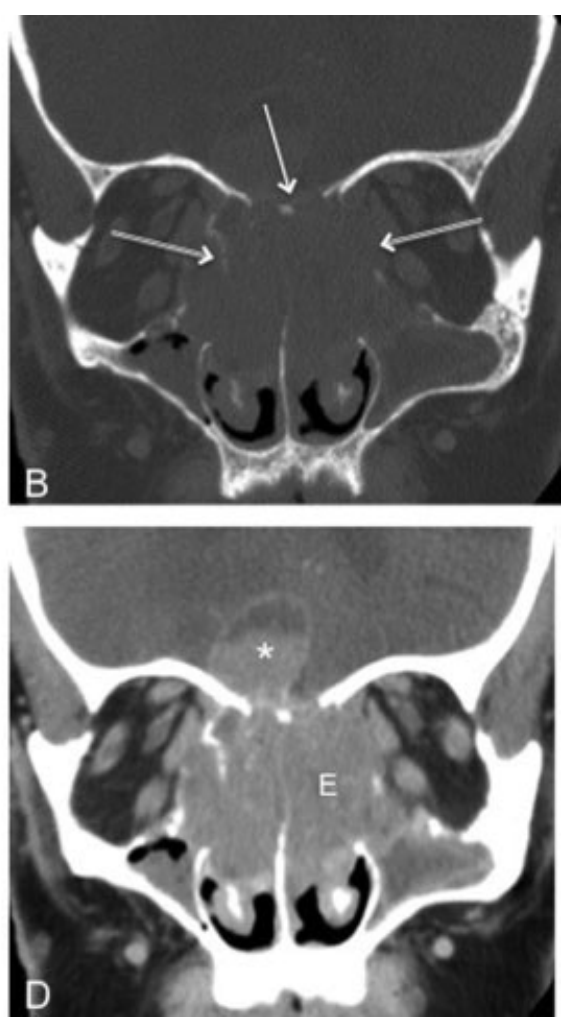

Fig. 1 Coronal computed tomography of the face in (A, B) bone and (C, D) soft tissue algorithms demonstrates avidly enhancing esthesioneuroblastoma (E) filling the nasal cavity and extending into orbits and intracranially (asterisk). The mass has eroded the floor of the anterior cranial fossa (single arrow) and lamina papyracea bilaterally (double arrow). 

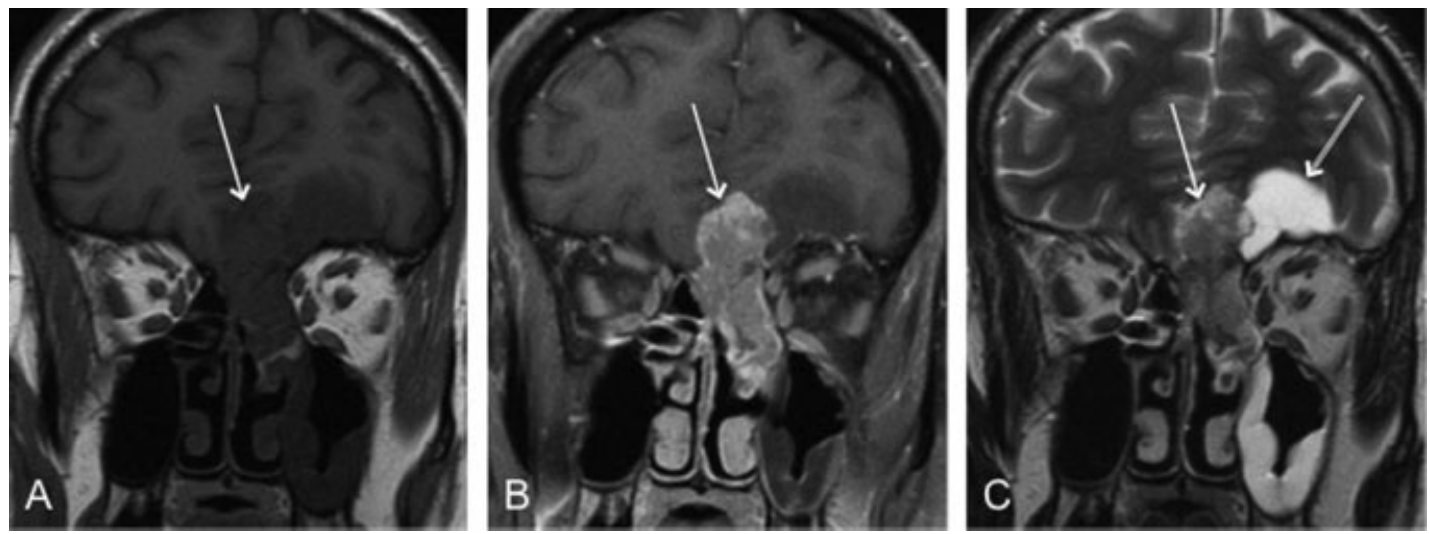

Fig. 2 Coronal (A) T1-weighted, (B) contrast-enhanced, and (C) T2-weighted images from magnetic resonance imaging demonstrate a low T1 intensity and avidly enhancing nasal vault mass extending intracranially (arrow). (C) The T2-weighted sequence shows peritumoral cyst (double arrow).

speckled calcifications are occasionally present. ${ }^{21} \mathrm{CT}$ is also useful to assess regional neck and distant metastasis. ${ }^{20,22}$

The most important information gained from MRI is differentiating entrapped secretions from neoplasm because CT is unreliable for this distinction (- Fig. 2). ${ }^{22,23}$ MRI is also superior in defining the soft tissue extent and offers a more accurate assessment of suspected intracranial, orbital, or skull base invasion, and perineural spread of tumor. ${ }^{7,22,24}$ MRI is also excellent at distinguishing dural involvement from parenchymal involvement (-Fig. 3). ${ }^{23}$

ENB is usually hypointense to gray matter on T1-weighted images and intermediate to hyperintense on T2-weighted
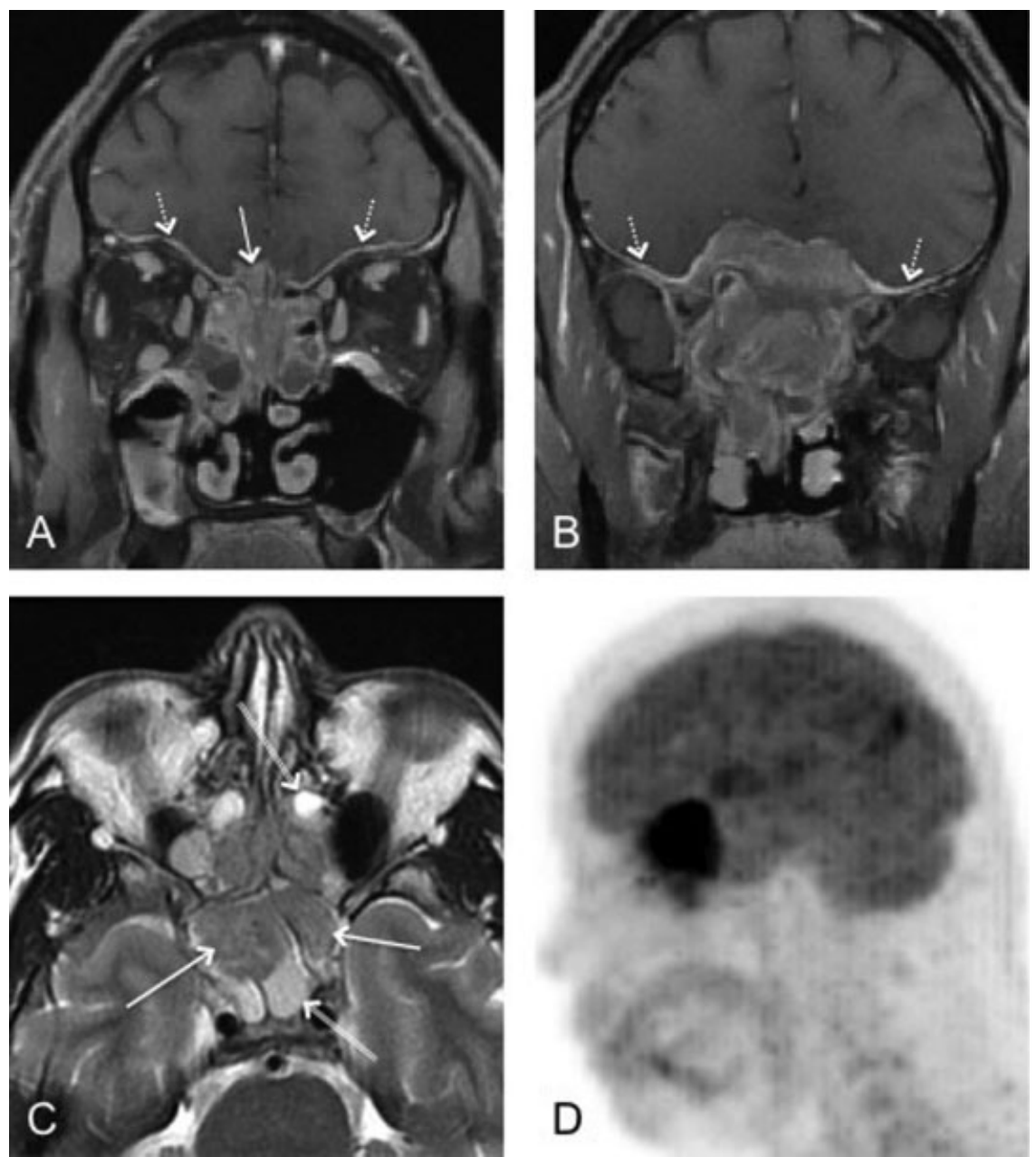

Fig. 3 (A, B) Utility of magnetic resonance imaging in the evaluation of dural involvement as demonstrated by coronal fat-saturated contrastenhanced images (dashed arrow). Intracranial extension fills the right olfactory groove (arrow in A). (C) Axial T2-weighted image shows a clear distinction between low-intensity esthesioneuroblastoma (arrows) and high-intensity trapped secretions (double arrows). (D) Sagittal reformatted image from positron emission tomography shows avid tracer uptake within the nasal vault mass with a large intracranial component. 
sequences (-Fig. 2). The tumor demonstrates avid and homogeneous enhancement except for occasional areas of necrosis or hemorrhage. Trapped secretions in adjacent sinuses are $\mathrm{T} 2$ hyperintense and differentiated from the tumor. The presence of intracranial cysts is highly suggestive of, but not diagnostic of ENB. Som et al studied 54 patients who had sinonasal lesions with intracranial extension and found only three patients with intracranial cysts, but all three had ENB. ${ }^{25}$

Bony destruction can be seen but frequently not as well as with CT. MRI, however, is much more accurate in the evaluation of subtle orbital and intracranial invasion including rare subarachnoid seeding. MRI fat-saturated sequences help distinguish tumor from orbital fat and muscle: a smooth bowing of the tumor-fat interface suggests that the lesion is contained by periorbital fascia, whereas an irregular margin favors frank invasion of the orbit. ${ }^{26,27}$ However, the definitive diagnosis of invasion of dura and periorbital tissues is possible only at surgery. ${ }^{27}$

Imaging of the neck in patients with ENB is crucial because neck metastases are found at presentation in $5 \%$ of patients. ${ }^{7}$ Further, it has been estimated that $>23 \%$ of patients may eventually develop cervical lymph node metastases. ${ }^{17}$ One of the most frequent distant metastasis is to bone, with the spine cited as the most common location (86\%). ${ }^{28}$ Cases of asymptomatic bone metastases have been described, and therefore a bone scan should be included in the diagnostic work-up. ${ }^{7}$

The assessment of recurrent tumor must include both CT and MRI. The imaging characteristics of the recurrent tumor do not differ from its appearance at initial presentation. ${ }^{29}$ The following protocol for follow-up has been suggested: contrast-enhanced MRI performed 2 to 4 months after completion of all therapy, and then repeated every 4 to 6 months for 5 years and then annually for the patient's lifetime. In addition, an annual chest radiograph should be performed to exclude the presence of metastases. ${ }^{14}$

Scintigraphic evaluation of ENB has been reported with technetium-99m methylene diphosphonate, indium-111 bleomycin complex, indium-111 octreotide, technetium$99 \mathrm{~m}$ ethylcysteinate dimer, and radioiodinated metaiodobenzylguanidine. ${ }^{12,30-32}$ More recently, positron emission tomography (PET) with F-18-labeled fluorodeoxyglucose was used in the staging of ENB in a case with ectopic Cushing syndrome. ${ }^{33}$ PET-CT was also found to be accurate not only in staging but also in the posttherapeutic restaging of ENB. ${ }^{34}$ While promising, the data on PET and other scintigraphic methods in evaluation of recurrent or residual ENB are very limited.

Finally, because ENB is most often a nonvascular tumor, diagnostic and therapeutic angiographic techniques have no place in the diagnostic work-up of this entity. ${ }^{35}$

\section{Conclusion}

Although the imaging characteristics of ENB are somewhat nonspecific, there are patterns of the disease, such as Kadish grade $C$, which should strongly suggest this disorder. Metastatic disease, usually regional, occurs frequently with fairly predictable involvement of level II nodes but also level I and III and retropharyngeal nodes that are difficult to assess clinically. Finally, a suggested follow-up scheme is recommended to detect recurrences at the earliest possible time.

\section{References}

1 Broich G, Pagliari A, Ottaviani F. Esthesioneuroblastoma: a general review of the cases published since the discovery of the tumour in 1924. Anticancer Res 1997;17(4A):2683-2706

2 Jethanamest D, Morris LG, Sikora AG, Kutler DI. Esthesioneuroblastoma: a population-based analysis of survival and prognostic factors. Arch Otolaryngol Head Neck Surg 2007;133(3):276-280

3 Thompson LD. Olfactory neuroblastoma. Head Neck Pathol 2009; 3(3):252-259

4 Elkon D, Hightower SI, Lim ML, Cantrell RW, Constable WC. Esthesioneuroblastoma. Cancer 1979;44(3):1087-1094

5 Simon JH, Zhen W, McCulloch TM, et al. Esthesioneuroblastoma: the University of Iowa experience 1978-1998. Laryngoscope 2001;111(3):488-493

6 Kadish S, Goodman M, Wang CC. Olfactory neuroblastoma. A clinical analysis of 17 cases. Cancer 1976;37(3):1571-1576

7 Bradley PJ, Jones NS, Robertson I. Diagnosis and management of esthesioneuroblastoma. Curr Opin Otolaryngol Head Neck Surg 2003;11(2):112-118

8 Dulguerov P, Calcaterra T. Esthesioneuroblastoma: the UCLA experience 1970-1990. Laryngoscope 1992;102(8):843-849

9 Dulguerov P, Allal AS, Calcaterra TC. Esthesioneuroblastoma: a meta-analysis and review. Lancet Oncol 2001;2(11):683-690

10 Morita A, Ebersold MJ, Olsen KD, Foote RL, Lewis JE, Quast LM. Esthesioneuroblastoma: prognosis and management. Neurosurgery 1993;32(5):706-714; discussion 714-715

11 Polin RS, Sheehan JP, Chenelle AG, et al. The role of preoperative adjuvant treatment in the management of esthesioneuroblastoma: the University of Virginia experience. Neurosurgery 1998; 42(5):1029-1037

12 Jekunen AP, Kairemo KJ, Ramsay HA, Kajanti MJ. Imaging of olfactory neuroblastoma by In-111 bleomycin complex. Clin Nucl Med 1996;21(2):129-131

13 Jekunen AP, Kairemo KJA, Lehtonen HP, Kajanti MJ. Treatment of olfactory neuroblastoma. A report of 11 cases. Am J Clin Oncol 1996;19(4):375-378

14 Slevin NJ, Irwin CJR, Banerjee SS, Gupta NK, Farrington WT. Olfactory neural tumours - the role of external beam radiotherapy. J Laryngol Otol 1996;110(11):1012-1016

15 Girod D, Hanna E, Marentette L. Esthesioneuroblastoma. Head Neck 2001;23(6):500-505

16 Olsen KD, DeSanto LW. Olfactory neuroblastoma. Biologic and clinical behavior. Arch Otolaryngol 1983;109(12):797-802

17 Rinaldo A, Ferlito A, Shaha AR, Wei WI, Lund VJ. Esthesioneuroblastoma and cervical lymph node metastases: clinical and therapeutic implications. Acta Otolaryngol 2002;122(2):215-221

18 Monroe AT, Hinerman RW, Amdur RJ, Morris CG, Mendenhall WM. Radiation therapy for esthesioneuroblastoma: rationale for elective neck irradiation. Head Neck 2003;25(7):529-534

19 Davis RE, Weissler MC. Esthesioneuroblastoma and neck metastasis. Head Neck 1992;14(6):477-482

20 Howell MC, Branstetter BF IV, Snyderman CH. Patterns of regional spread for esthesioneuroblastoma. AJNR Am J Neuroradiol 2011; 32(5):929-933

21 Manelfe C, Bonafé A, Fabre P, Pessey JJ. Computed tomography in olfactory neuroblastoma: one case of esthesioneuroepithelioma and four cases of esthesioneuroblastoma. J Comput Assist Tomogr 1978;2(4):412-420

22 Ahmad A, Branstetter BF IV. CT versus MR: still a tough decision. Otolaryngol Clin North Am 2008;41(1):1-22, v

23 Branstetter BF IV, Weissman JL. Role of MR and CT in the paranasal sinuses. Otolaryngol Clin North Am 2005;38(6):1279-1299, x 
24 Ling FTK, Kountakis SE. Advances in imaging of the paranasal sinuses. Curr Allergy Asthma Rep 2006;6(6):502-507

25 Som PM, Lidov M, Brandwein M, Catalano P, Biller HF. Sinonasal esthesioneuroblastoma with intracranial extension: marginal tumor cysts as a diagnostic MR finding. AJNR Am J Neuroradiol 1994; 15(7):1259-1262

26 Sievers KW, Greess H, Baum U, Dobritz M, Lenz M. Paranasal sinuses and nasopharynx CT and MRI. Eur J Radiol 2000;33(3): 185-202

27 Dulguerov P, Allal AS. Nasal and paranasal sinus carcinoma: how can we continue to make progress? Curr Opin Otolaryngol Head Neck Surg 2006;14(2):67-72

28 Koka VN, Julieron M, Bourhis J, et al. Aesthesioneuroblastoma. J Laryngol Otol 1998;112(7):628-633

29 Pickuth D, Heywang-Köbrunner SH. Imaging of recurrent esthesioneuroblastoma. Br J Radiol 1999;72(863):1052-1057
30 Shanley DJ, Buckner AB. Esthesioneuroblastoma demonstrated on bone scan. Correlation with CT and MRI. Clin Nucl Med 1992; 17(3):231-232

31 Bustillo A, Telischi F, Weed D, et al. Octreotide scintigraphy in the head and neck. Laryngoscope 2004;114(3):434-440

32 Prado GL, Itabashi Y, Noda H, Miura H, Mariya Y, Abe Y. Olfactory neuroblastoma visualized by Technetium-99m-ECD SPECT. Radiat Med 2001;19(5):267-270

$33 \mathrm{Yu}$ J, Koch CA, Patsalides A, et al. Ectopic Cushing's syndrome caused by an esthesioneuroblastoma. Endocr Pract 2004;10(2): 119-124

34 Nguyen BD, Roarke MC, Nelson KD, Chong BW. F-18 FDG PET/CT staging and posttherapeutic assessment of esthesioneuroblastoma. Clin Nucl Med 2006;31(3):172-174

35 Rosengren JE, Jing BS, Wallace S, Danziger J. Radiographic features of olfactory neuroblastoma. AJR Am J Roentgenol 1979;132(6):945-948 